\title{
ANALYSIS OF ACCURACY AND GRAMMATICAL COMPLEXITY IN THE WRITING OF UPPER INTERMEDIATE AND ADVANCED LEARNERS OF ENGLISH
}

\author{
ANÁLISIS DE LA CORRECCIÓN Y LA COMPLEJIDAD \\ GRAMATICAL EN LA ESCRITURA DE ESTUDIANTES DE INGLÉS \\ DE NIVELES INTERMEDIO-ALTO Y AVANZADO
}

\author{
ANA CRISTINA LAHUERTA MARTÍNEZ \\ Universidad de Oviedo, España \\ lahuerta@uniovi.es
}

\section{ABSTRACT}

The aim of the present study is twofold. In the first place, it aims at examining and comparing the written compositions of two groups of undergraduates enrolled in a University Degree in English Studies, using as measures accuracy and grammatical complexity. It also intends to describe the development of the morphological, syntactic, punctuation and spelling errors as English is used by these learners. A total of 100 learners of English as a foreign language participated in the study. They were divided into two groups according to their Oxford Placement Test score: group A was formed by 36 advanced students ( $\mathrm{C} 1$ as per the Common European Framework of Reference for Languages (CEFR)); and group B was made up of 64 upper intermediate students (B2 as per the CEFR). The analysis of the compositions collected showed significant differences between advanced and upper intermediate students both in complexity and in accuracy. The figures indicated that there was an improvement trend between B2 and C1. However, the differences between groups were significant only in spelling and in punctuation errors. Although the upper intermediate and advanced EFL groups investigated were mainly found to be dominated by progress, there were nevertheless some cases of error stabilization and regression tendencies.

Keywords: Writing, accuracy, complexity, grammatical morphemes, syntax, university.

\section{RESUMEN}

El objetivo de este trabajo es doble: (a) se ocupa de examinar y comparar las composiciones de estudiantes universitarios de inglés como lengua extranjera, utilizando como medidas 
la precisión y la complejidad gramatical; (b) además, pretende describir la evolución de los errores morfológicos, sintácticos, de pronunciación y de ortografía cometidos por estos alumnos. Los participantes en el estudio fueron 100 aprendices de inglés como lengua extranjera, que fueron divididos en dos grupos de acuerdo a su resultado en la Prueba Oxford Placement Test. Así, el grupo A estaba formado por 36 aprendices de nivel avanzado (C1 según el Marco Común Europeo de Referencia para las Lenguas o MCERL) y el grupo B por 64 estudiantes de nivel intermedio alto (B2 según el MCERL). Los resultados de los análisis de las composiciones recogidas para llevar a cabo el estudio mostraron diferencias significativas entre los dos grupos tanto en precisión como en complejidad. Se observó una tendencia de mejora entre los dos niveles $\mathrm{B} 2$ y C1 analizados. Sin embargo, las diferencias entre grupos solamente resultaron significativas en los errores de puntuación y ortografía. En conclusión, aunque los dos grupos investigados muestran una tendencia hacia la mejora en la competencia escrita, se encontraron casos de estabilización y de regresión en los errores.

Palabras clave: Escritura, precisión, complejidad, morfemas gramaticales, sintaxis, universidad.

Recibido: 22.03.2016. Aceptado: 19.04.2017.

\section{INTRODUCTION}

WTithin a view of language as a complex, dynamic system, Larsen-Freeman (2006:590) suggests a new way of understanding learner language development, "not discrete and stage-like but more like the waxing and waning of patterns". Within this perspective, linguistic subsystems, dimensions of language proficiency (accuracy, fluency, and complexity), and even individual elements of language interact in ways that are supportive, competitive, and conditional. They are supportive in that development in one of these subsystems, dimensions, or elements might depend upon the development in another. The competition is exemplified by the fact that "at one point in time, higher performance on one dimension of proficiency, say accuracy, can seemingly detract from performance in others, say fluency and complexity" (Larsen-Freeman, 2006; 593). Written competence as a subset of language competence is also complex and can only be explained by the interaction of different dimensions of language proficiency.

Within this perspective, the present study aims at examining two dimensions of written language proficiency, namely, grammatical complexity and accuracy, with an emphasis on error judgement. This study examines learners at two levels of proficiency, upper intermediate (B2) and advanced (C1) users according to the Common European Framework of Reference for Languages (Council of Europe, 2001). 


\section{REVIEW OF THE LITERATURE}

Accuracy can be defined as the absence of deviations from a particular linguistic norm, it is "the ability to be free from errors while using language to communicate in either writing or speech" (Wolfe-Quintero, Inagaki \& Kim, 1998:33). On the other hand, grammatical complexity means that a wide variety of basic and sophisticated structures are available and can be accessed quickly (Wolfe-Quintero et al., 1998). Grammatical complexity is important "because of the assumption that language development entails, among other processes, the growth of an L2 learner's syntactic repertoire and her or his ability to use that repertoire appropriately in a variety of situations" (Ortega, 2003: 492). This means that learners have both basic and sophisticated structures at their disposal as their grammatical ability and proficiency increase, and that (it is assumed) L2 writers can then choose the structure that best fits the context and the purpose of the communicative situation (Wolfe-Quintero et al., 1998).

A developmental analysis of the accuracy of a second language writer involves counting the number of errors or types of errors in writing samples (Wolfe-Quintero et al., 1998). One approach is the analysis of how many errors occur in relation to production units such as words, clauses, or T-units (e.g. Bardovi-Harlig and Bofman, 1989; Homburg, 1984; Kuiken \& Vedder, 2008). Another approach has been to focus on whether a structural unit of some type is error-free, whether clauses, sentences or T-units (e.g. Tedick, 1990). Other researchers have examined specific error categories such as verb-noun collocations (e.g., Laufer \& Waldman, 2011), and a variety of other errors and error combinations (e.g., Chan, 2010). Recent studies like Thewissen (2013) investigate second language accuracy development counting errors in relation to the number of times a learner could potentially have committed such an error. Let's see these studies in some detail.

Homburg (1984:94) followed Nas (1975) classification of errors into three categories according to their effect on comprehensibility. These included firstdegree errors, where minor errors in spelling, word choice, or grammar did not interfere with comprehension; second-degree errors, where serious departures in spelling, word choice, or grammar could only be understood within the writing's larger context; and third-degree errors, where spelling, word choice, or grammatical structures made interpretation nearly impossible. Homburg (1984) found that five of the measures differentiated among the three proficiency levels studied: second-degree errors per T-unit, dependent clauses per composition, words per sentence, coordinating conjunctions per composition, and error-free T-units per composition (when all errors were taken into account).

More recently, Kuiken and Vedder (2008) used a similar scheme, which identified first-, second- and third-degree errors based on the "communicative seriousness of the errors" (p. 53) without regard for error categories such as spelling or 
morphosyntactic problems. Using this approach, they found statistically significant differences between the first- and second-degree errors per T-unit across all levels of task complexity.

Bardovi-Harlig and Bofman (1989) examined the relationship between grammatical complexity, and overall accuracy in the written English of two groups of advanced adult foreign language learners divided according to their performance on a placement test (1989:20). The analysis of errors revealed that the two groups could be distinguished by the number of errors they produced, but the errors they produced showed the same distribution among error types (p. 23). The smallest difference between groups was shown in syntactic errors. The greatest difference between groups was their production of lexical-idiomatic errors, which was significant. The difference in morphological errors was only weakly significant. Both groups produced the greatest number of errors in grammatical morphemes, with fewer errors in lexical choice, and the smallest number of errors in syntax (1989:24).

Tedick's (1990) study on ESL graduate students' writing performance found out highly significant differences among three course levels (beginning, intermediate and advanced) for holistic score, mean length of T-units, number of errorfree T-units, and mean length of error-free T-units in the students' writing performance. Beginning and intermediate students were not significantly different from one another in terms of mean length of T-units and overall length, but both were significantly different from the advanced group on these measures. The intermediate and advanced groups were not significantly different from one another with regard to holistic scores, number of error-free T-units, and mean length of errorfree T-units, but both were significantly different from the beginning group with regard to these measures (1990:131-132).

Thewissen (2013:77) investigated second language accuracy development via an error-tagged version of an EFL learner corpus. Findings showed a nonlinear development as only two error types displayed a linear, progress-only type of development (viz., the total errors and lexical single errors). The data, in fact, pointed to different types of development for the EFL groups across the $\mathrm{B} 1$ to $\mathrm{C} 2$ continuum (2013:95). Results distinguished between progress-only errors (i.e., B1 > B2 > C1 $>\mathrm{C} 2$ ), stabilization-only errors (i.e., [B1/B2/C1/C2]), progress \& stabilization errors (e.g., $\mathrm{B} 1>[\mathrm{B} 2 / \mathrm{C} 1 / \mathrm{C} 2]$ and $[\mathrm{B} 1 / \mathrm{B} 2]>[\mathrm{B} 2 / \mathrm{C} 1]>[\mathrm{C} 1 / \mathrm{C} 2])$, and error types with marked regression (i.e., B1 < B2). The results suggest that, within the B1 to $\mathrm{C} 2$ range, development in accuracy is most marked between the lower and upper intermediate levels, hence pointing to a possible accuracy threshold at B1, that is, a level after which accuracy can generally be said to remain stable. Conversely, accuracy is a less strongly discriminating feature at the higher B2 to C2 levels, where many error types show a tendency toward stabilization (2013:95).

As mentioned above, some studies have examined specific error categories. 
Chan (2010) identified lexicogrammatical error types in the writing of university and secondary education Cantonese English as a second language (ESL) learners. Errors from the lexical level included vocabulary compensation, synonym confusion, and inaccurate directionality; errors from the syntactic level included calquing, existential structures, incorrect ordering of adverbials, misuse of conjunctions, omission of subjects, misuse of prepositions, misuse of relative clauses, punctuation problems, and independent clauses as subjects; and those from the discourse level included periphrastic-topic constructions. Laufer and Waldman (2011) investigated the use of English verb-noun collocations in the writing of native speakers of Hebrew at three proficiency levels. The data revealed that learners at all three proficiency levels produced far fewer collocations than native speakers, that the number of collocations increased only at the advanced level, and that errors, particularly interlingual ones, continued to persist even at advanced levels of proficiency.

Grammatical complexity measures include measures that analyse the clauses, sentences, or T-units in terms of each other (e.g., clauses per sentence, dependent clauses per T-unit, T-units per sentence), and measures that analyse the presence of specific grammatical structures in relation to clauses, T-units, or sentences (e.g., passives per sentence, nominal per T-unit, connectors per sentence) (Wolfe-Quintero et al., 1998:69). Early studies using grammatical complexity measures include Ishikawa (1995, cited in Wolfe-Quintero et al., 1998) and Larsen-Freeman (2006)).

Ishikawa (1995, cited in Wolfe-Quintero et al., 1998) compared the ratio of clauses to sentences of two groups of low-proficiency EFL students. These were given different practice tasks (writing out or answering questions about the same picture stories) in order to determine which task type was more related to increase in writing proficiency. She found that there was a significant increase in clauses per sentences for one of the groups but not the other, although both groups progressed in clauses per sentence.

Larsen-Freeman (2006) examined the oral and written production of five Chinese learners of English, using measures of fluency, accuracy, and grammatical and lexical complexity. Findings showed that over a six-month period, participants were writing more fluently and accurately, and their writing had become more complex in grammar and in vocabulary. However, whereas group averages could be represented by a more or less smoothly ascending curve, some individual performances regressed and progressed, and others remained somewhat unchanged over time. The rate of change fluctuated for different participants at different times and the largest rate change occurred for accuracy.

Recent studies use measures of fluency, accuracy, and complexity to compare writing performance under different conditions (Ghavamnia, Tavakoli \& Esteki, 2013), to analyse raters' judgments of various rating measures (Kuiken and Ved- 
der (2014), or to compare writing performance at different instruction periods (Knoch, Rouhshad \& Storch, 2014; Knoch, Rouhshad, Oon \& Storch, 2015; Godfrey and Treacy, 2014).

Ghavamnia et al. (2013:34) conducted a study with forty intermediate EFL learners in order to see if any significant difference existed in the writing performance of the participants under two planning conditions, pre-task planning and online planning in relation to complexity, accuracy, and fluency. In the pre-task planning condition, the participants were given 10 minutes to plan, and $20 \mathrm{~min}$ utes to write the actual written narrative, whereas in the online planning condition, the participants took as much time as they needed to complete the writing task without any time limitations. The findings of this study showed that the pre-task planning group produced more complex and fluent writings, whereas the online planning group produced more error free clauses indicating a more accurate writing performance. The author concludes (2013:42) that this study suggests that pre-task planning has a positive effect on the fluency and complexity of the written output, whereas online planning has an influential impact on the accuracy of the written product.

Kuiken and Vedder (2014) investigated the relationship in L2 writing between raters' judgments of communicative adequacy and linguistic complexity. The participants were learners of Italian L2 and learners of Dutch L2, with a proficiency level ranging from $\mathrm{A} 2$ to $\mathrm{B} 1$. All participants were subjected to two writing tasks, comprising a short argumentative text. All texts were scored by means of measures of syntactic complexity, lexical diversity, and accuracy. Findings showed that overall ratings of linguistic complexity were correlated with lexical diversity and accuracy, but not with syntactic complexity. Raters of both Italian and Dutch reported attaching more importance to communicative adequacy (content, use of arguments, rhetorical organization, style and general comprehensibility) than to linguistic complexity (grammar, lexicon, spelling and accuracy).

Knoch et al. (2014) examined students' ESL writing proficiency following a year's study in an Australian university. The study used a longitudinal design (one year) and investigated writing development using global writing scores, as well as measures of accuracy, fluency, grammatical and lexical complexity. The results of the study showed that global scores of writing showed no change over time. The only significant improvement participants in the current study showed was in their fluency (measured via text length). That is, they could write longer texts in the time allowed. There were no observed gains in accuracy, syntactic and lexical complexity (2014: 8-10).

Knoch et al. (2015) examined undergraduate students' L2 (ESL) writing proficiency following a three-year degree study in an L2-medium university. A range of measures was used to assess writing, including global and discourse measures 
(accuracy, fluency, complexity). Consistent with Knoch et al. (2014), global scores of writing did not improve significantly over the three years of degree study. In terms of the discourse measures, also consistent with Knoch et al. (2014), fluency (measured via word count) increased significantly over three years of degree study, suggesting that participants were able to produce more words within the same allotted time, whereas accuracy, grammatical and lexical complexity did not change over time (2015:50).

Godfrey and Treacy (2014) examined the writing of eight university learners of French-four during study abroad and four in on-campus courses-over the course of a semester. This study applied measures focused on the complexity, accuracy, fluency, and form-function relationships of writing samples collected at the beginning and end of the semester. Results (2014: 56) showed that progress toward more advanced academic L2 writing occurred for both groups of students, although in different ways. Students in both groups improved the syntactic complexity in their writing, although the domestic group improved more than the study abroad group did. Both groups' use of linguistic forms and expressions to make supported claims and use appropriate discourse markers improved, while the on-campus group increased their hedging of such claims more than the study abroad group.

A number of studies carry out a developmental analysis of the grammatical complexity of second language writers counting the number of cohesive devices, particularly connectors, in relation to words or clauses. Comparisons between essays written by native speakers of English and Swedish EFL students (Altenberg and Tapper, 1998), and between native speakers of English and Japanese EFL learners (Narita, Sato \& Sugiura, 2004) revealed that learners used fewer connectors in their writing than the native speakers, and they tended to overuse and underuse certain types of connectors.

Some of these studies showed inappropriate use of conjunctions. For example, Granger and Tyson (1996) carried out a corpus-based study on connector usage in essays written by French students. Written essays were collected from French EFL students and native speakers, to be investigated in terms of conjunct usage. Results showed that eight conjuncts - "however", "instead", "though", "yet", "hence", "therefore", "thus" and "then"- were underused by the French students. As for misuse, the researchers stated that learners were often insensitive to the "stylistic restrictions" of certain connectors (Granger \& Tyson 1996:23). Ting (2003) and Ong (2011) examined Chinese undergraduate EFL students' expository writings. They found that inappropriate use of adversative and additive conjunctions represented the most frequent conjunction errors committed by the learners in both studies. Among the errors found in both studies were the use of adversative conjunctions without any explicit or implied contrast and the use of additive 
conjunctions without the cohesive effect of adding to new or additional information. In both studies, the number of errors in using temporal conjunctions was the smallest.

Wei-yu Chen (2006), who carried out a corpus-based connector study on the writing of master students in Taiwan found out that certain conjunctions (e.g. causal conjunctions like "besides" and "therefore") were used inappropriately by some of the learners. Likewise, Hamed (2014), who investigated the use of conjunctions in argumentative essays written by EFL fourth-year undergraduate Libyan students majoring in English, showed that the students used the conjunctions inappropriately, and that the adversative conjunctions posed the most difficulty for the learners, followed by additives and causals. Kwan and Yunnus (2014) carried out a mixed-methods error analysis study in order to examine the cohesive errors in the writing of English as a second language pre-service teachers of differing language proficiency levels-medium and high-level. The study found that the medium-level pre-service teachers made the most errors in lexical cohesion, reference and conjunction cohesion categories. However, high-level pre-service teachers made more errors in lexical cohesion, ellipsis and reference. Collocation proved the most difficult form of cohesion for both groups of pre-service teachers, while high-level pre-service teachers made more errors in ellipsis than the medium-level pre-service teachers.

Crossley, Kyle \& McNamara (2016:1-2) examined the development of local cohesion (i.e. devices related to sentence level cohesion such as connectives), global cohesion (i.e., devices related to cohesion between larger chunks of texts such as word overlap between paragraphs in a text), and text cohesive devices (i.e., lexical diversity) in L2 writing. Participants were L2 university students enrolled in a semester-long upper-level English for Academic Purposes (EAP) course. Results showed that L2 writers generally wrote essays that demonstrated greater local, global, and text cohesion from the beginning until the end of the semester. Specifically, significant differences were observed between the initial and final essays in the use of connectives, particularly causal ones. The results of the study also indicated that indices of cohesion were predictors of human judgments of text organization and overall essay quality for L2 writing.

\section{STUDY}

The review of the literature above reveals contrasting findings. Thus, some studies show significant differences among course levels in holistic scores, and improvement over the course of time in accuracy, grammatical and lexical complexity (e.g. Larsen-Freeman, 2006; Tedick, 1990). Some research also reveals improvement in L2 writing over time, although in different ways depending on the students 
investigated (Godfrey and Treacy, 2014). On the contrary, studies by Knoch et al. $(2014,2015)$ found that the participants' written performance improvement over time was evident only in the holistic rating, and in fluency not finding any significant changes over time in accuracy or complexity. Different results have also been obtained regarding error development: whereas some studies showed a linear error development, and the same distribution among error types (e.g. Bardovi-Harlig and Bofman, 1989), others like Thewissen (2013) showed a nonlinear development of errors. Finally, while most studies show difficulties in the use of cohesive devices (e.g. Wei-yu Chen, 2006; Hamed, 2014), others show improvement over time in connective use (Crossley et al., 2016)

In view of these contradictory results, the aim of the present study is twofold: (a) it aims to examine and compare the writing products of EFL undergraduates using as measures accuracy and grammatical complexity; (b) it also intends to describe the evolution of the use of morphological, syntactic, punctuation and spelling errors by both groups of learners. Early SLA researchers such as Corder (1967) had a point in claiming that errors constitute a useful window into the processes of second language acquisition, acting as potential indicators of the developmental stages learners are likely to have reached. This article will show what examination of learners' errors can reveal in this respect.

\subsection{Subjects}

A total of 100 learners of English as a foreign language (i.e., learners of English in a non-English-speaking country) participated in the study. They were undergraduates enrolled in a Degree in English Studies in a Spanish University. They were all native speakers of Spanish and their average age was 20 years. They were divided into two groups according to their Oxford Placement Test score: group A was formed by 36 students with a score between 150 and 169 (advanced); and group B was made up of 64 students with a score between 135 and 149 (upper intermediate). Data collection took place at the end of the 2014-15 academic year.

Regarding the methodology used in their English classes, they all followed a communicative approach. Writing instruction and activities were part of their EFL curriculum. They received writing assignments in their content subject classes in addition to their English language classes.

\subsection{Procedure}

Compositions were collected as the basis of this study. The students were allotted 45 minutes to address one of two topics in their essays: "Discuss the growing 
popularity of audio books", and "First-world societies suffer from an obsessive dependence on technological gadgets".

\subsection{Data analysis}

For purposes of this study, the essays were scored along the following parameters: grammatical accuracy, complexity and surface errors. For accuracy, the measure used were error-free sentence ratio (total number of error-free sentences divided by total number of sentences). Regarding the grammatical complexity measures, we used the sentence complexity ratio (total number of sentences divided by total number of clauses) in the writing samples.

As additional measures, we also calculated the punctuation error ratio (total number of punctuation errors divided by total number of words), and spelling error ratio (total number of spelling errors divided by total number of words).

Errors were analysed and scored as syntactic and morphological following Bardovi-Harlig and Bofman (1989:21). Thus, syntactic errors consisted of errors of word order, errors resulting from the absence of constituents, and errors in combining sentences. Word-order errors included errors in the order of major constituents (such as pragmatically unacceptable deviations from SVO) and minor constituents (such as adverb placement). Errors resulting from the absence of constituents included deletion of a major constituent (subject, verb, or object), and sentence fragments that lacked finite verbs. Errors in sentence combining included errors in complementation, relativization, or coordination. Morphological errors included errors in nominal morphology (plural, number agreement, uncountable nouns, and compounds), errors in verbal morphology (tense, subjectverb agreement, and passive formation), errors in determiners and articles, errors in prepositions, and errors in derivational morphology (e.g., lack of suffixes, etc.). We also included errors in connectors into this category.

For the analysis, the essays were segmented in sentence and clausal units in Microsoft Excel sheets and they were manually analysed and annotated for the different types of errors studied. All essays were analysed, annotated, and counted by one researcher who was a native speaker of Spanish and were checked by a second researcher that was a native speaker of English. The annotation took 10 to 15 minutes per essay on average. The main difficulties encountered concerned the inclusion of an error within the appropriate category or subcategory. When these discrepancies occurred, they were discussed among the researchers until an agreement was reached. Errors of each type at each level of proficiency were counted in relation to the total number of words in the learner's composition. 


\section{RESULTS}

A statistical analysis was carried out with the program R Development Core Team 2012, 2.15 version.

We calculated mean scores and standard deviations, and used paired-samples Student $\mathrm{t}$ tests and Welch tests to check for the significance of the differences observed between the two groups. The Pearson product-moment correlation coefficient was used for the study of the relations between two numerical variables. The Pearson's chi-squared test was used for comparisons between two qualitative variables. We regard as statistically significant differences those in which p-value was lower than 0.05 .

A Student test shows significant differences between advanced and upper intermediate students both in complexity and in accuracy (see Table I below). Group A (advanced students) outscored Group B (upper intermediate students) in grammatical complexity as measured by the total number of sentences per clause $(\mathrm{M}=$ 41.88, Student test, $\mathrm{p}<0.05)$. This group also outperformed Group B in accuracy as measured by error-free sentences $(M=47.53$, Student test, $\mathrm{p}<0.05)$.

Table I. Advanced and upper intermediate students' written competence as measured by accuracy and complexity measures.

\begin{tabular}{lllll}
\hline & Group & Mean & SD & $P$ \\
\hline \multirow{2}{*}{ Sentence complexity ratio } & Group A & 41.88 & 40.23 & $\mathbf{0 . 0 4}$ \\
& Group B & 37.52 & 36.78 & \\
Error-free sentence ratio & Group A & 47.53 & 47.02 & $\mathbf{0 . 0 1}$ \\
& Group B & 25.15 & 20.00 & \\
\hline
\end{tabular}

Group B exhibited a higher error mean in each of the error categories, namely, grammatical morphemes and syntax, as well as punctuation and spelling. The figures indicate that there is progress between B2 and C1 (an error mean of 3.64 total errors at $\mathrm{C} 1$ vs 9.01 at B2) although the statistical analysis shows the differences between groups to be significant only in spelling errors and in punctuation errors $(M=0.45 ; M=0.27$, Student test $p<0.05),(M=0.62 ; M=0.24$, Student test $\mathrm{p}<0.05)$ (Table II). These error categories show a significant developmental pattern as they display a statistically significant difference in behaviour between both levels. 
Table II. Distribution of errors for advanced and upper intermediate students.

\begin{tabular}{lllll}
\hline & Group & Mean & SD & $P$ \\
\hline \multirow{2}{*}{ Syntactic errors ratio } & Group A & 0.72 & 0.38 & \\
& Group B & 1.66 & 1.21 & 0.11 n.s \\
Morphological error ratio & Group A & 1.59 & 1.45 & \\
& Group B & 3.93 & 2.52 & \multirow{2}{*}{0.16 n.s } \\
Spelling error ratio & Group A & 0.27 & 0.32 & \multirow{2}{*}{0.04} \\
Punctuation error ratio & Group B & 0.45 & 0.32 & \multirow{2}{*}{0.04} \\
& Group A & 0.24 & 0.00 & \\
\hline
\end{tabular}

Although Group A showed a lower error mean percentage than Group B, the distribution of errors is virtually the same for both groups. Morphological errors were the most common in Group A, followed by errors in syntax, spelling errors, and finally punctuation errors. In Group B, the order of error frequency is the same except that punctuation errors are more frequent than spelling errors.

The distribution of error types within the category of grammatical morphemes appears in Table III. The number and percentage of students with at least an error of each type was calculated. As we can observe, Group A exhibits a lower percentage of each type of morphological errors except for three error types. That is, most errors show a developmental pattern with the number of errors decreasing as proficiency increases.

We also observe some similarity in the groups' distribution among error types within the morphological category. The most frequent errors in Group A are errors in article usage (the no article use), and use of incorrect prepositions, followed by errors in nominal morphology (number agreement, uncountable nouns and compounds), tense misuse, incorrect connectors, and incorrect determiners. In Group B, the most frequent errors are errors in article usage (the no article use), and use of incorrect preposition, followed by tense misuse, incorrect connectors, incorrect determiners, and errors in nominal morphology (number agreement, uncountable nouns and compounds).

One error type showed no sign of improvement across the B2-C1 performance range: incorrect use of no article. This finding pointed to article usage as a rather improvement resistant area for the EFL groups under research. Tense usage also seemed to be a rather difficult area for both groups. Errors in prepositions, tense and connectors show a tendency toward improvement; however, they remain weak areas, even for the advanced group. It is worth noting that the percentage of each of these errors is quite high (for example, the error percentage of incorrect prepositions is 67.19 at $\mathrm{B} 2$ vs 65.71 at $\mathrm{C} 1$; the error percentage of tense 
misuse is 65.63 at $\mathrm{B} 2$ vs 45.71 at $\mathrm{C} 1$; the error percentage of incorrect connectors is 60.94 at $\mathrm{B} 2$ vs 45.71 at $\mathrm{C} 1$ ).

Surprisingly, it is the higher C1-level compositions that include more errors of two types, namely errors in nominal morphology (number agreement, uncountable nouns and compounds), and two errors in verbal morphology (-s omitted, and incorrect article). It is worth noting the high percentage of errors in nominal morphology. These included errors in number agreement, errors in uncountable nouns, errors in compounds, errors in adjectives and adverbs. Looked at exclusively from an accuracy point of view, the rise in the number of errors between B2 and $\mathrm{C} 1$ could be interpreted as a sign of regression.

Table III. Distribution of errors in grammatical morphemes by percentage of occurrence for groups A and B (advanced and upper intermediate students).

\begin{tabular}{|c|c|c|c|c|}
\hline & \multicolumn{2}{|c|}{ Group B } & \multicolumn{2}{|c|}{ Group A } \\
\hline & Num. & $\%$ & Num. & $\%$ \\
\hline \multicolumn{5}{|l|}{ Nominal morphology } \\
\hline Plural & 10 & $15 ., 63$ & 4 & 11.43 \\
\hline $\begin{array}{l}\text { Number agreement, uncountable } \\
\text { nouns and compounds }\end{array}$ & 34 & 53.13 & 20 & 57.14 \\
\hline \multicolumn{5}{|l|}{ Verbal morphology } \\
\hline \multicolumn{5}{|l|}{ Subject-verb agreement } \\
\hline -s omitted & 3 & 4,69 & 2 & 5.71 \\
\hline -s overgeneralized & 18 & 28.13 & 1 & 2.86 \\
\hline \multicolumn{5}{|l|}{ Tense } \\
\hline Ill formed & 4 & 6,25 & 2 & 5.71 \\
\hline misuse & 42 & 65.63 & 16 & 45.71 \\
\hline Passives & 4 & 6.25 & 2 & 5.71 \\
\hline Connectors & 39 & 60.94 & 16 & 45.71 \\
\hline \multicolumn{5}{|l|}{ Articles } \\
\hline Incorrect article & 5 & 7.81 & 3 & 8.57 \\
\hline No article & 64 & 100.00 & 35 & 100.00 \\
\hline Unnecessary article & 29 & 45.31 & 9 & 25.71 \\
\hline \multicolumn{5}{|l|}{ Determiners } \\
\hline Incorrect determiners & 38 & 59.38 & 7 & 20,00 \\
\hline No determiner & 10 & 15.63 & 4 & 11,43 \\
\hline Unnecessary determiner & 11 & 17.19 & 5 & 14,29 \\
\hline
\end{tabular}


Continuation Table III.

\begin{tabular}{|l|r|r|r|r|}
\hline Prepositions & & & & \\
\hline Incorrect preposition & 43 & 67.19 & 23 & 65.71 \\
\hline No preposition & 9 & 14.06 & 2 & 5.71 \\
\hline Unnecessary preposition & 12 & 18.75 & 3 & 8.57 \\
\hline Derivational morphology & 14 & 21.88 & 1 & 2.86 \\
\hline
\end{tabular}

Table IV gives the distribution of syntactic errors for both groups. Group A exhibits a lower percentage of each type of syntactic errors with one exception: word order. That is, although syntactic errors show a developmental pattern with the number of errors decreasing as proficiency increases, there is a case of regression.

The distribution of error types within the category of syntax is almost the same for both groups. Thus, in Group A, errors in complementation are the most frequent ones, followed by word order, sentence fragments, deletion of constituents, relative clauses, and coordination. In Group B, the most frequent errors are complementation, followed by word order, sentence fragments, deletion of constituents, coordination, and relative clauses. As we can observe, some of these errors have a high error percentage at both levels of proficiency (for example, the error percentage of complementation is 66.67 at $\mathrm{B} 2$ vs 55.17 at $\mathrm{C} 1$; the error percentage of sentence fragments is 47.37 at $\mathrm{B} 2$ vs 27.59 at $\mathrm{C} 1$ ).

Table IV. Distribution of syntactic errors by percentage of occurrence for groups A and B advanced and upper intermediate students.

\begin{tabular}{|l|r|r|r|r|}
\hline & \multicolumn{2}{|c|}{ Group B } & \multicolumn{2}{c|}{ Group A } \\
\hline & Num. & \multicolumn{1}{c|}{$\%$} & Num. & \multicolumn{1}{c|}{$\%$} \\
\hline Word order & 34 & 59.65 & 39 & 61.03 \\
\hline Complements & 38 & 66.67 & 16 & 55.17 \\
\hline Relative clauses & 5 & 18.77 & 5 & 17.24 \\
\hline Coordination & 7 & 12.28 & 3 & 10.34 \\
\hline Fragments & 27 & 47.37 & 8 & 27.59 \\
\hline Missing constituents & 15 & 26.32 & 6 & 20.69 \\
\hline
\end{tabular}

We also calculated the mean percentage of morphological and syntactic errors (see Tables V and VI). Group B shows a higher mean percentage of morphological errors (with three exceptions, namely $-s$ omitted, ill formed tenses, and absence of determiners) as well as a higher mean percentage of syntactic errors. 
Differences were statistically significant only in three morphological errors types: -s generalised $(M=0.12 ; M=0.01$; Welch test $\mathrm{p}<0.05)$, use of incorrect determiners $(\mathrm{M}=0.30 ; \mathrm{M}=0.10$; Student test $\mathrm{p}<0.05)$, and derivational morphology $(\mathrm{M}=0.08$; $\mathrm{M}=0.01$; Welch test $\mathrm{p}<0.05)$. These error categories showed significant progress between $\mathrm{B} 2$ and $\mathrm{C} 1$. The number of these errors steadily and significantly decreases as proficiency increases. From these results, it can be safely assumed that these three morphological categories are indeed mastered by the time students reach a C1-level of proficiency.

Table V. Morphological error mean percentage of Groups A and B (advanced and upper intermediate students).

\begin{tabular}{|c|c|c|c|c|c|}
\hline & \multicolumn{2}{|c|}{ Mean } & \multicolumn{2}{|c|}{ SD } & \multirow{2}{*}{$P$} \\
\hline & Group $A$ & Group B & Group A & Group B & \\
\hline \multicolumn{6}{|l|}{ Nominal morphology } \\
\hline Plural & 0.04 & 0.08 & 0.00 & 0.00 & 0.19 \\
\hline $\begin{array}{l}\text { Number agreement and } \\
\text { possessive }\end{array}$ & 0.28 & 0.52 & 0.29 & 0.26 & 0.46 \\
\hline \multicolumn{6}{|l|}{ Verbal morphology } \\
\hline \multicolumn{6}{|l|}{ Subject-verb agreement } \\
\hline -s omitted & 0.02 & 0.01 & 0.00 & 0.00 & 0.73 \\
\hline -s overgeneralized & 0.01 & 0.12 & 0.00 & 0.00 & 0.01 \\
\hline \multicolumn{6}{|l|}{ Tense } \\
\hline Ill formed & 0.06 & 0.02 & 0.00 & 0.00 & 0.35 \\
\hline misuse & 0.22 & 0.70 & 0.00 & 0.32 & 0.43 \\
\hline Passives & 0.02 & 0.02 & 0.00 & 0.00 & 0.7 \\
\hline Connectors & 0.20 & 0.45 & 0.00 & 0.29 & 0.14 \\
\hline \multicolumn{6}{|l|}{ Articles } \\
\hline Incorrect article & 0.04 & 0.04 & 0.00 & 0.00 & 0.95 \\
\hline No article & 0.06 & 0.18 & 0.00 & 0.00 & 0.34 \\
\hline Unnecessary article & 0.11 & 0.32 & 0.00 & 0.00 & 0.2 \\
\hline \multicolumn{6}{|l|}{ Determiners } \\
\hline Incorrect determiners & 0.10 & 0.30 & 0.00 & 0.30 & 0.01 \\
\hline No determiner & 0.06 & 0.05 & 0.00 & 0.00 & 0.79 \\
\hline Unnecessary determiner & 0.06 & 0.17 & 0.00 & 0.00 & 0.37 \\
\hline \multicolumn{6}{|l|}{ Prepositions } \\
\hline Incorrect preposition & 0.32 & 0.55 & 0.30 & 0.30 & 0.47 \\
\hline
\end{tabular}


Continuation Table V.

\begin{tabular}{|c|r|r|r|r|r|}
\hline No preposition & 0.03 & 0.04 & 0.00 & 0.00 & 0.56 \\
\hline Unnecessary preposition & 0.03 & 0.08 & 0.00 & 0.00 & 0.1 \\
\hline Derivational morphology & 0.01 & 0.08 & 0.00 & 0.00 & $\mathbf{0 . 0 1}$ \\
\hline
\end{tabular}

Table VI. Syntactic error mean percentage of Groups A and B (advanced and upper intermediate students).

\begin{tabular}{|l|r|r|r|r|r|}
\hline & \multicolumn{2}{|c|}{ Mean } & \multicolumn{2}{|c|}{ SD } & \multirow{2}{*}{ P } \\
\cline { 1 - 5 } & Group A & Group B & Group A & Group B & \\
\hline Word order & 0.09 & 0.17 & 0.00 & 0.00 & 0.07 \\
\hline Complements & 0.23 & 0.83 & 0.00 & 0.32 & 0.22 \\
\hline Relative clauses & 0.04 & 0.04 & 0.00 & 0.00 & 0.92 \\
\hline Coordination & 0.03 & 0.03 & 0.00 & 0.00 & 0.86 \\
\hline Fragments & 0.13 & 0.39 & 0.00 & 0.00 & 0.14 \\
\hline Missing constituents & 0.06 & 0.11 & 0.00 & 0.00 & 0.2 \\
\hline
\end{tabular}

\section{DISCUSSION}

A significant difference in written competence between the two groups examined is evidenced by their different performance in accuracy and complexity. The advanced user group outperforms the upper intermediate user group in accuracy and grammatical complexity as measured by error-free sentence ratio and by the total number of sentences per clause, respectively. Advanced users write more accurately, and their writing is grammatically more complex. These results are in line with those of Tedick (1990), Larsen Freeman (2006), and Godfrey and Treacy (2014) that show differences among course levels and a tendency towards improvement in written competence over time.

Although the results obtained show that accuracy, and syntactic and morphological complexity seem to progress in parallel, as defended by Wolfe-Quintero et al. (1998), our findings also provide some degree of empirical substantiation for the Larsen-Freeman's (2006) claim that learning itself is very rarely linear and that L2 development involves more than steadily climbing from one level to the next. The nonlinear aspect of development is to some extent borne out by our study of error patterns, where some error types did not display a linear, progress-only type of development. Although the upper intermediate and advanced EFL groups investigated have mainly been found to be dominated by progress, there are nev- 
ertheless some cases of stabilization and regression tendencies.

In our view, these tendencies do not necessarily imply an absence of learning. As Thewissen (2013), states, both stabilization and regression may in fact at times be the result of growing L2 capacities, such as increasing levels of complexity, especially at the more advanced levels. Depending on where the stabilization occurs, it may be that a ceiling effect (Milton \& Meara, 1995, in Thewissen, 2013) is at play. According to Thewissen (2013), errors that are affected by a potential ceiling effect should be interpreted as a sign that, although errors remain in terms of raw occurrences, a significant amount of learning has already taken place.

The analysis of errors shows that students exhibit a stronger and more complete acquisition of syntax than of grammatical morphemes, revealed by the lower error mean in syntax. This is consistent with Bardovi-Harlig and Bofman's (1989) study with advanced adult foreign language learners. This study showed relatively strong and uniform acquisition of syntax by all learners, whereas development in the grammatical morphemes appeared to be incomplete and variable.

Although the figures show a tendency toward improvement, it was not strong enough to be picked up statistically except for three morphological errors. Grammatical morphemes such as articles, verb tenses, and connectors, and syntactic categories like complementation and word order continue to pose problems for these upper intermediate and advanced students. Article usage constitutes a rather improvement resistant area for the EFL groups. Bardovi-Harlig and Bofman (1989) also found that articles were difficult for their advanced language learners. The literature agrees that articles present varying levels of difficulty depending on the learners' proficiency level as well as their L1 background. In Spanish, the use of an article is compulsory and this appears to explain why some English uses remain a problematic area for learners. Moreover, according to Master (2002), frequency related reasons also partly account for the difficulty involved in article use: Articles are "among the most frequently occurring function words in the language [...], making continuous conscious rule application difficult over an extended stretch of discourse" (p. 332).

Tense usage seems to be a rather difficult area for both groups. Previous studies on tenses (e.g., Bardovi-Harlig \& Reynolds, 1995; Han, 2002; Hawkins \& Buttery, 2010; Thewissen, 2013) conclude that tenses remain a weak spot, even for more advanced groups. This result is quite disheartening as this is a grammatical area that receives a lot of attention in the students' curriculum.

The inappropriate use of connectors is in line with the results of a number of studies (e.g., Hamed, 2014; Ong, 2011; Ting, 2003; Wei-yu Chen, 2006) previously reviewed. Frequent errors committed by our students were the use of connectors (e.g. "first of all", "first", "so"...) with no justification in the previous sentence or paragraph. There were also instances of missing connectors to join sentences or paragraphs. When we analysed single connector choice we found that 
learners tended to use a limited set of connectors ("and", "but", "because", and "so" are the most frequent ones). This is consistent with research by Altenberg \& Tapper (1998), and Granger \& Tyson (1996). These studies conclude that learners of English tend to function with a closed set of favourite connectors that they use over and over again.

Regarding syntax, we have observed that, although syntactic errors show a developmental pattern with the number of errors decreasing as proficiency increases, there is a case of regression (word order). The most frequent errors observed included errors in the order of major constituents, that is, cases of unacceptable deviations from SVO and minor constituents (such as adverb placement). Word order errors are identified as common error types among EFL advanced learners in Bardovi-Harlig and Hofman (1989).

In addition to grammar and syntax, the present study examined the developmental paths displayed by errors in important L2 areas such as punctuation and spelling. Although previous research studies found that punctuation errors were an improvement-resistant feature across proficiency levels (e.g. Thewissen, 2013), our study shows that these error categories diminish as proficiency increases. This constitutes a key finding as punctuation and spelling have received scarce developmental attention to date.

\section{CONCLUSIONS AND PEDAGOGICAL IMPLICATIONS}

According to the findings of the study, we can conclude that progress was a regular trend among the learners being studied. This is a positive conclusion, considering that they learned English in an instructed rather than in a naturalistic setting. However, this encouraging conclusion cannot deny the fact that development in the grammatical morphemes and in syntax appeared to be weak, incomplete and variable for the two groups of learners investigated.

In our view, these findings have some pedagogical implications. In the first place, more pedagogical attention should be given to the areas that cause difficulties to EFL learners, particularly within morphology and syntax. EFL teachers should be aware of those areas that remain difficult and improvement-resistant even at high levels of proficiency. Secondly, the results also call for changes in teaching methods and show the importance of adopting a discourse-based EFL teaching methodology when teaching a foreign language, and when approaching a writing task. Teaching methods based on learners' error awareness and on a discourse rather than a sentence point of view should be adopted as a way of both making students aware of their weak areas and overcoming these difficulties through the use of authentic language in discourse. 


\section{REFERENCES}

Altenberg, B. \& Tapper, M. (1998). The use of adverbial connectors in advanced Swedish learners' written English. In S. Granger (ed.). Learner English on Computer (pp. 80-93). Harlow: Addison Wesley Longman Limited.

Bardovi-Harlig, K. \& Bofman, T. (1989). Attainment of syntactic and morphological accuracy by advanced language learners. SSLA, 11, 17-34.

Bardovi-Harlig, K. \& Reynolds, D.W. (1995). The role of lexical aspect in the acquisition of tense and aspect. TESOL Quarterly, 29, 107-131.

Chan, A.Y.W. (2010). Toward a Taxonomy of Written Errors: Investigation into the Written Errors of Hong Kong Cantonese ESL Learners. TESOL Quarterly, 44, 2, 295-319.

Corder, S. P. (1967). The significance of learners' errors. International Review of Applied Linguistics in Language Teaching, 4, 161-179.

Council of Europe. (2001). Common European Framework of Reference for Languages: Learning, Teaching, Assessment. Cambridge: Cambridge University Press.

Crossley, S.A., Kyle, K., \& McNamara, D. S. (2016). The development and use of cohesive devices in L2 writing and their relations to judgments of essay quality. Journal of Second Language Writing, 32, 1-16.

Ghavamnia, M, Tavakoli, M. \& Esteki, M. (2013). The effect of pre-task and online planning conditions on complexity, accuracy, and fluency on EFL learners' written production. Porta Linguarum, 20, 31-43.

Godfrey, L. \& Treacy, C. (2014). Change in French second language writing in study abroad and domestic contexts. Foreign Language Annals, 47(1), 48-65.

Granger, S. \& Tyson, S. (1996). Connector usage in the English essay writing of native and non-native EFL speakers of English. World Englishes, 15 (1), 17-27.

Hamed, M. (2014). Conjunctions in argumentative writing of Libyan tertiary students. English Language Teaching, 7(3), 108-120.

Han, Z. (2002). A study of the impact of recasts on tense consistency in L2 output. TESOL Quarterly, 36, 543-572.

Hawkins, J. \& Buttery, P. (2010). Criterial features in learner corpora: Theory and illustrations. English Profile Journal, 1, 1-23.

Homburg, T.J. (1984). Holistic Evaluation of ESL Compositions: Can it be validated objectively? TESOL Quarterly, 18, 1, 87-107.

Ishikava, S. (1995). Objective measurement of low-proficiency of EFL narrative writing. Journal of Second Language Writing, 4, 51-70.

Knoch, U., Rouhshad, A. \& Storch, N. (2014). Does the writing of undergraduate ESL students develop after one year of study in an English-medium university? Assessing Writing, 21: 1-17.

Knoch, U., Rouhshad, A., Oon, S. P., \& Storch, N. (2015). What happens to ESL 
students' writing after three years of study at an English medium university? Journal of Second Language Writing, 28, 39-52.

Kuiken, F. \& Vedder, I. (2008). Cognitive task complexity and written output in Italian and French as a foreign language. Journal of Second Language Writing, 17, 48-60.

Kuiken, F. \& Vedder, I. (2014). Rating written performance: What do raters do and why? Language Testing, 31(3), 329-348.

Kwan, L.S.L. \& Yunnus, M.M. (2014). Cohesive Errors in Writing among ESL Pre-Service Teachers. English Language Teaching, 7, 11, 130-150.

Larsen-Freeman, D. (2006). The emergence of complexity, fluency, and accuracy in the oral and written production of five Chinese learners of English. Applied Linguistics, 27(4), 590-619.

Laufer, B. \& Waldman, T. (2011). Verb-noun collocations in second language writing: A Corpus analysis of learners' English. Language Learning, 61(2), $647-$ 672.

Master, P. (2002). Information structure and English article pedagogy. System, 30, 331-348.

Milton, J., \& Meara, P. (1995). How periods abroad affect vocabulary growth in a foreign language. ITL Review of Applied Linguistics, 107/108, 17-34.

Narita, M., Sato, C. \& Sugiura, M. (2004). Connector usage in the English essay writing of Japanese EFL Learners. Paper presented at the Fourth International Conference on Language Resources and Evaluation. Lisbon, Portugal.

Nas, G. (1975). Determining the communicative value of written discourse produced by L2 learners. Utrecht, The Netherlands: Institute of Applied Linguistics.

Ong, J. (2011). Investigating the Use of Cohesive Devices by Chinese EFL Learners. The Asian EFL Journal Quarterly, 11(3), 42-65.

Ortega, L. (2003). Syntactic complexity measures and their relationship to L2 proficiency: A research synthesis of college-level L2 writing. Applied Linguistics, 24(4), 492-518.

R (R Development Core Team, 2012), version 2.15. R: A language and environment for statistical computing. Vienna, Austria. Available in http://www.rproject.org/ (ISBN 3-900051-07-0).

Tedick, D. J. (1990). ESL writing assessment: Subject-matter knowledge and its impact on performance. Studies in Second Language Acquisition, 9, 123-143.

Thewissen, J. (2013). Capturing L2 Accuracy Developmental Patterns: Insights From an Error-Tagged EFL Learner Corpus. The Modern Language Journal, $97,77-101$.

Ting, F. (2003). An Investigation of Cohesive Errors in the Writing of PRC Tertiary EFL Students (Unpublished Master's Thesis). National University of Singapore, Singapore.

Wei-yu Chen, C. (2006). The use of conjunctive adverbials in the academic pa- 
pers of advanced Taiwanese EFL learners. International Journal of Corpus Linguistics, 11(1), 113-130.

Wolfe-Quintero, K., Inagaki, S. \& Kim, H. (1998). Second language development in writing: Measures of fluency, accuracy, and complexity. Hawai' i: University of Hawai' i at Manoa. 